\title{
A Simultaneous Analytical Method for Duplex Identification of Porcine and Horse in the Meat Products by EvaGreen based Real-time PCR
}

\author{
Ergün Sakalar*, Seyma Özçirak Ergün, Emine Akar \\ Department of Bioengineering, Faculty of Engineering, Canakkale Onsekiz Mart University, \\ 17020 Canakkale, Turkey
}

\begin{abstract}
A duplex real-time polymerase chain reaction (PCR) based assay for the detection of porcine and horse meat in sausages was designed by using EvaGreen fluorescent dye. Primers were selected from mitochondrial 12S rRNA and 16S rRNA genes which are powerful regions for identification of horse and porcine meat. DNA from reference samples and industrial products was successfully extracted using the GIDAGEN ${ }^{\circledR}$ Multi-Fast DNA Isolation Kit. Genomes were identified based on their specific melting peaks (Mp) which are $82.5^{\circ} \mathrm{C}$ and $78^{\circ} \mathrm{C}$ for horse and porcine, respectively. The assay used in this study allowed the detection of as little as $0.0001 \%$ level of horse meat and $0.001 \%$ level of porcine meat in the experimental admixtures. These findings indicate that EvaGreen based duplex realtime PCR is a potentially sensitive, reliable, rapid and accurate assay for the detection of meat species adulterated with porcine and horse meats.
\end{abstract}

Keywords: duplex real-time PCR, EvaGreen, horse, porcine, unspecific amplicon

Received December 19, 2014; Revised March 23, 2015; Accepted May 7, 2015

\section{Introduction}

Meat and meat species adulteration is a sizeable problem in the food industry. The detection of meat adulteration is a major issue in the food industries (Commission Directive 2001/101/E). Product quality and origin in meat products are very important issues for consumers, vendors and government agencies. There are many reasons for the disclosure of adulterated meat products, such as health problems, unfair competition and religious beliefs (Rastogi et al., 2007).

Porcine meat is a potential source of adulteration for higher value meat, such as beef and lamb, due to the similarity in color and texture. When undeclared, porcine is an undesirable contaminant for health reasons, as well as religious reasons, because of the potential introduction of allergens, bacteria, and parasites (Asensio et al., 2008; Wissiack et al., 2003). Furthermore, mechanically recovered meats that have been used increasingly in the food industry are prone to various forms of pork adulteration

\footnotetext{
*Corresponding author: Ergun Sakalar, Department of Bioengineering, Faculty of Engineering, Canakkale Onsekiz Mart University, 17020 Canakkale, Turkey. Tel: +902862180018 (Ext: 2749), Fax:+902862180541, E-mail: esakalar@comu.edu.tr
}

(Yaakob et al., 2012).

A coordinated control plan was launched about horse meat in the European Union (EU) to constitute the proliferation of fraudulent practices in the marketing of certain foods, and the results stated the presence of unlabeled horse meat in approximately $5 \%$ of the tested products (EU/99/2013; European Commission 2013). The "horse meat scandal" did not lead to a health scandal; however, it was a good example of food fraud that triggered social concerns and mistrust of meat products which did not declare all species in the ingredient list (Cawthorn et al., 2013; Pegels et al., 2014).

There are many techniques to detect and identify the origin of species, especially in industrial meat products during the last decades. In recent years, molecular authentication methodologies based on PCR amplification have been developed, and these methods have been successfully applied for species authentication in meat products (Meyer et al., 1995; Natonek-Wisniewska et al., 2009; Stamoulis et al., 2010). Real-time PCR, especially, has become the most promising technique for rapid and practical detection of different meat species (Şakalar, 2013). The main advantages of real-time PCR are high sensitivity, high specificity, excellent efficiency, and no post-PCR steps that reduce risks of cross-contamination. Some sci- 
entists (Fajardo et al., 2008; Martín et al., 2009; Wang et al., 2006) have suggested that multiplex real-time PCR combined with fluorescent dye is not applicable. The uniformity of each species-specific amplicon in conjunction with fluorophor-specific probes would make these assays amenable to multi-color multiplex detection, whereas fluorescent dye based detection would not (Elizaquivel and Aznar, 2008, Walker et al., 2004). In fact, recent research shows that the use of fluorescent dye may result in a high multiplexing index in less time, in a single reaction (Fukushima et al., 2005; Pafundo et al., 2009; Şakalar and Abas 1yanık 2012) as shown by schematic determination of porcine and horse meats by EvaGreen based duplex real time PCR (Fig. 1).

In the present study, the method of EvaGreen based real-time PCR was developed to specifically detect porcine and horse DNA in simultaneous reactions using the $12 \mathrm{~S}$ rRNA gene region of porcine and the $16 \mathrm{~S}$ rRNAtRNA $t$ (Leu) gene regions of horse mt-DNA sequence and species specific primers.

\section{Materials and Methods}

\section{Preparation of meat samples}

Reference raw meat samples, horse and porcine, were purchased from local suppliers and pasteurized at $85^{\circ} \mathrm{C}$ for $60 \mathrm{~min}$ to form a model admixture as follows: The porcine $(25 \mathrm{~g})$ and horse $(25 \mathrm{~g})$ meats were homogenized by tissue $\&$ cell lab homogenizer (WT500-S1, Germany) to form $50 \mathrm{~g}$ binary mixture. Of this binary mixture $5 \mathrm{~g}$ $(10 \%)$ was added to $45 \mathrm{~g}$ of sausage and then mixed by homogenizer. Following this stage, an admixture containing $10 \%$ porcine and horse meats was produced. As described herein, diluted admixtures (50 g) containing $0.0001,0.001,0.01,0.1,1$, and $10 \%(\mathrm{wt} / \mathrm{wt})$ porcine and horse meats were prepared within pasteurized $\left(85^{\circ} \mathrm{C}\right.$ for $60 \mathrm{~min}$ ) sausages which were produced from beef, chicken, soybean protein and additive materials such as spices

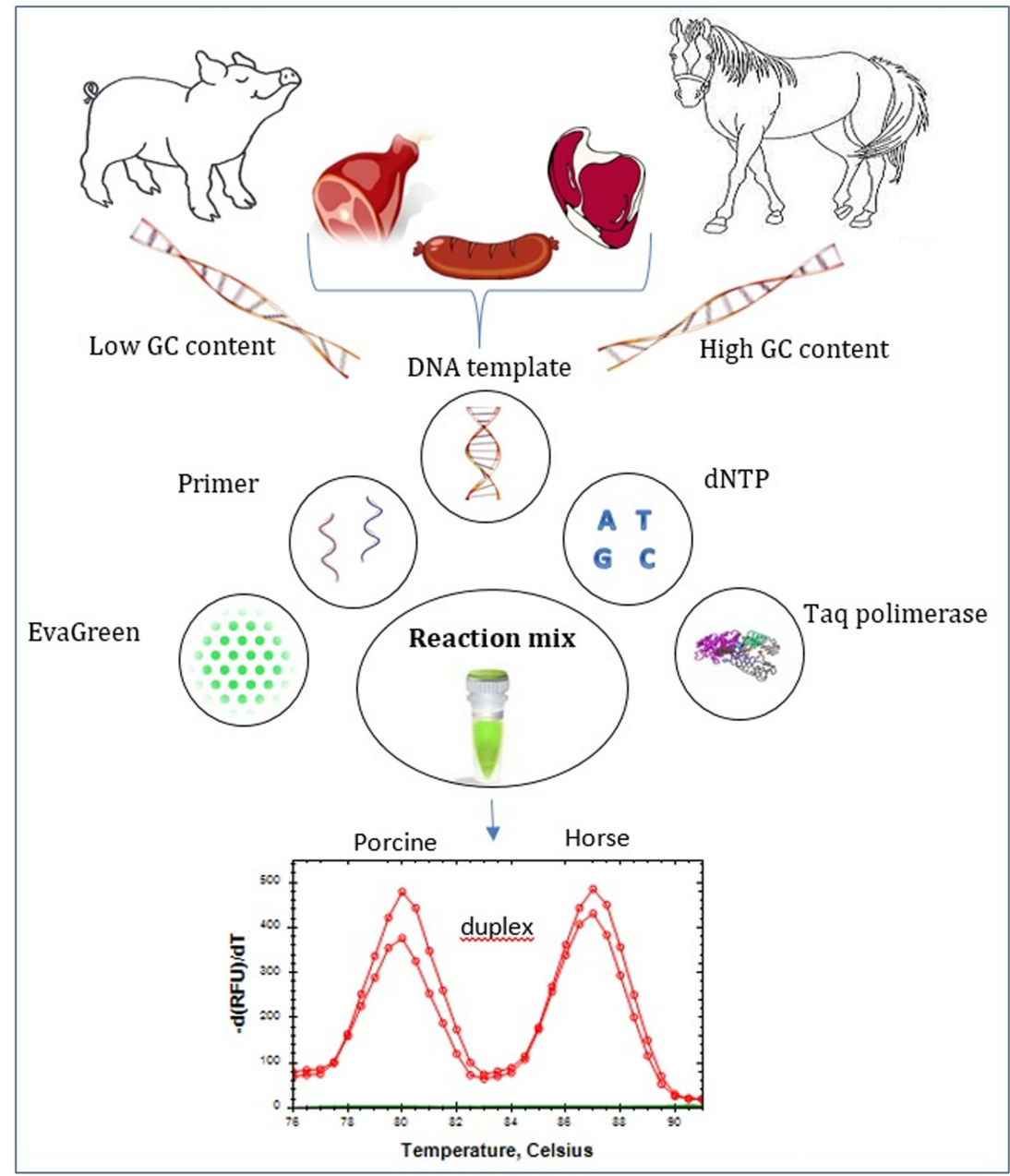

Fig. 1. Schematic determination of porcine and horse by EvaGreen based duplex real time PCR. 
by Meat Products Industry (Danet, Turkey). Model admixtures were produced in duplicate to confirm aforementioned assay used below (EvaGreen based duplex realtime PCR). They were directly transported to the Molecular Bioengineering Research Laboratory of Çanakkale 18 Mart University. All samples were stored until the extraction of the DNA at $20^{\circ} \mathrm{C}$ in order to prevent the enzymatic degradation of DNA.

\section{DNA extraction and quantification}

DNA was extracted from $100 \mathrm{mg}$ meat and sausage samples by using Multi-Fast DNA Isolation Kit (GIDAGEN ${ }^{\circledR}$, Turkey). A microplate reader device (Infinite ${ }^{\circledR}$ 200 PRO NanoQuant, Switzerland) was used to determine the concentration of DNA in the solution. The samples were exposed to ultraviolet light at 260 and $280 \mathrm{~nm}$. The ratio 260:280 was used to calculate the qualification of nucleic acids by the following formula: DNA concentration $=\mathrm{OD}_{260} \times$ extinction coefficient $(50 \mu \mathrm{g} / \mathrm{mL}) \times$ dilution factor. After the concentration of DNA $(150 \mu \mathrm{L})$ was measured, the DNA solutions were stored at $-20^{\circ} \mathrm{C}$ until used.

\section{Detection limit}

A mix of horse and porcine DNA was adjusted to 100 $\mathrm{ng} / \mu \mathrm{L}$ and subsequently serially diluted by 10 -fold increments yielding solutions of 10, 0.1, 0.01, 0.001, 0.0001, and $0.00001 \mathrm{ng} / \mu \mathrm{L}$ for the determination of the absolute detection limit of EvaGreen based real-time PCR. The admixtures of horse and porcine meats within sausages (episode 2.1) were used for the relative detection limit of the simultaneous analytical method which is the subject of this study.

\section{Primer design}

Porcine (Sus sacrofa) primers published by LópezAndreo et al. (2005) and horse (Equus caballus) primers published by Köppel et al. (2009) were used in this study. The specificity of each primer was controlled by an algorithm called BLAST (Basic Local Alignment Search Tool) of NCBI (National Center for Biotechnology Information). The primers used for species specific amplification of porcine genomic DNA were 5'-GAA AAA TCA TCG TTG TAC TTC AAC-3' (forward) and 5'-GGT CAA TGA ATG CGT TGT TGA T-3' (reverse). The primers used for species specific amplification of horse genomic DNA were 5'-CCA GAA TGG TAC TTC CTG TTT GC-3'(forward) and 5'-TAG AGA GGA TTA GGG CTA ATA CGC-3' (reverse). The sizes of the expected porcine and horse amplicons were 98 and 85 bp, respectively.

Optimization of the primer concentration and EvaGreen based duplex real-time PCR

The optimization of the primer quantity in the master mix was performed by mixing primers together at several quantities between 1 and 30 pmol. We started with equal concentrations of horse and porcine primers. The ratio of primer concentrations was adjusted afterwards, so that both amplicons were produced with high efficiency in the same reaction.

The PCR amplifications were performed in a final volume of $20 \mu \mathrm{L}$ containing $4 \mu \mathrm{L}$ of EvaGreen qPCR Mix (Solis Bio Dyne, Estonia), 10 pmol of horse primers, 14 pmol of porcine primers, and $200 \mathrm{ng}$ of DNA template using a CFX96 Touch ${ }^{\mathrm{TM}}$ real-time PCR Detection System (BioRad, Hercules, USA). After an initial heat denaturation step at $94^{\circ} \mathrm{C}$ for $10 \mathrm{~min}, 35$ cycles were programmed as follows: $94^{\circ} \mathrm{C}$ for $15 \mathrm{~s}, 58^{\circ} \mathrm{C}$ for $20 \mathrm{~s}$, and $72^{\circ} \mathrm{C}$ for $20 \mathrm{~s}$. All of the PCR reactions were applied in duplicate in two independent experiments.

At the end of each PCR, melting curve analysis tools of the CFX96 Touch ${ }^{\mathrm{TM}}$ real-time PCR Detection System (BioRad, Hercules, USA) were used to identify species specific Mp values of the amplified region of the template DNA that belong to reference meat samples. A melting curve analysis was programmed for its ramp formed from 72 to $95^{\circ} \mathrm{C}$ by raising $1{ }^{\circ} \mathrm{C}$ in each step. The process paused for $90 \mathrm{~s}$ to perform a pre-melt conditioning on the first step and for $5 \mathrm{~s}$ for each step afterwards.

\section{Quantification by standard curve method}

EvaGreen based real-time PCR amplifications were examined between specific primers and DNAs extracted from admixtures containing porcine and horse meat within sausages. The standard curve was constructed by using the $\mathrm{Cq}$ (cycle quantification) values obtained from the corresponding DNA concentration of $0.01,0.1,1$, and $10 \%$ (wt/wt) porcine and horse to check the applicability and sensitivity of the assay and detect unspecific amplicons.

\section{Results and Discussion}

\section{Improvement of EvaGreen based duplex real-time PCR}

In our study, the templates were amplified in real-time PCR followed by a melting curve analysis with EvaGreen and the CFX96 Touch ${ }^{\mathrm{TM}}$ real-time PCR Detection System (BioRad) after the horse and porcine primers were com- 


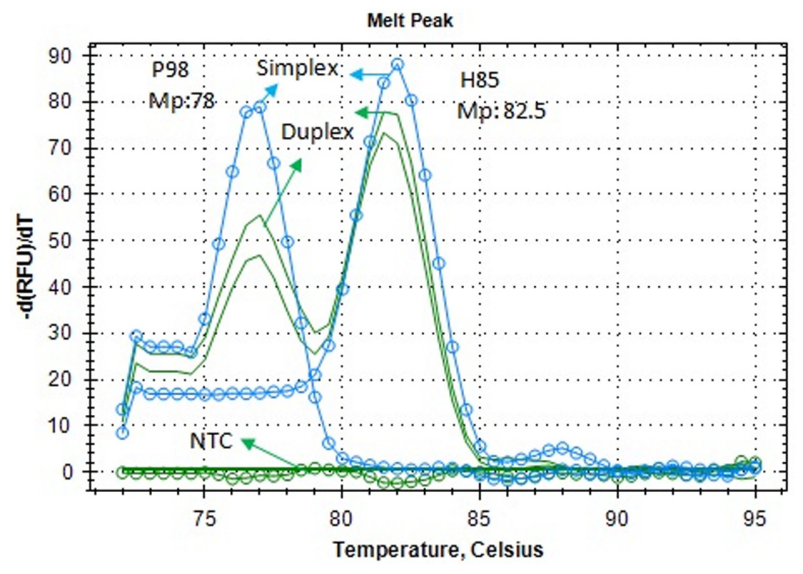

Fig. 2. Melting curve analysis of horse and porcine DNA by the simplex and simultaneous EvaGreen based realtime PCR. H: horse; P: porcine; Mp: Melt peak.

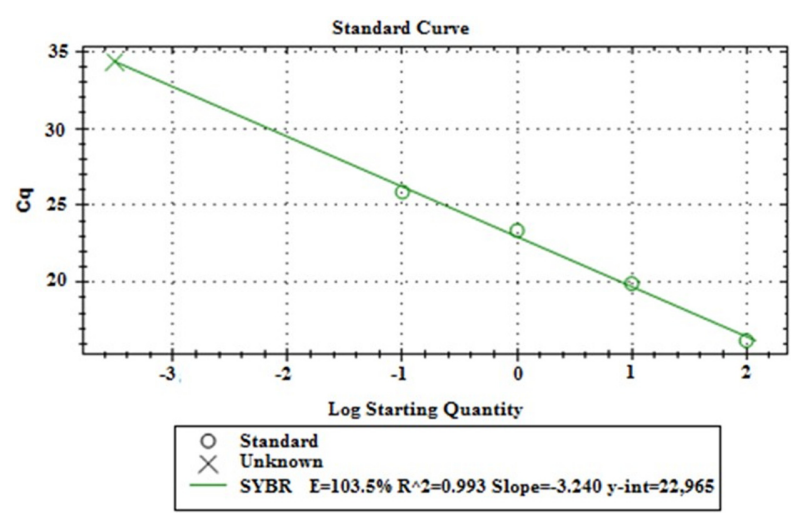

Fig. 3. Standart curve for quantification of unspecific amplicon.

bined for the multiplex reaction. Two am- plicons representing horse and porcine in the same reaction are shown in a graph representing the changes in fluorescence as a function of time $(-\mathrm{d}(\mathrm{RFU}) / \mathrm{dT})$ versus the temperature of the reaction products (Fig. 2). Horse and porcine amplicons were very readily separated through specific Mp (melt peak) values thanks to the different length and base compositions of the two amplicons. Eva Green based simultaneous real-time PCR finished with a single curve and two peaks as shown in Fig. 2. These peaks appeared in a specific location on the temperature axis at $82.5^{\circ} \mathrm{C}$ for horse and $78^{\circ} \mathrm{C}$ for porcine.

EvaGreen based simultaneous real-time PCR products were run on a $2.5 \%$ agarose gel stained with ethidium bromide to crosscheck. An agarose gel electrophoresis of the PCR products showed that horse and porcine samples produced bands of the expected size of 85 and $98 \mathrm{bp}$,

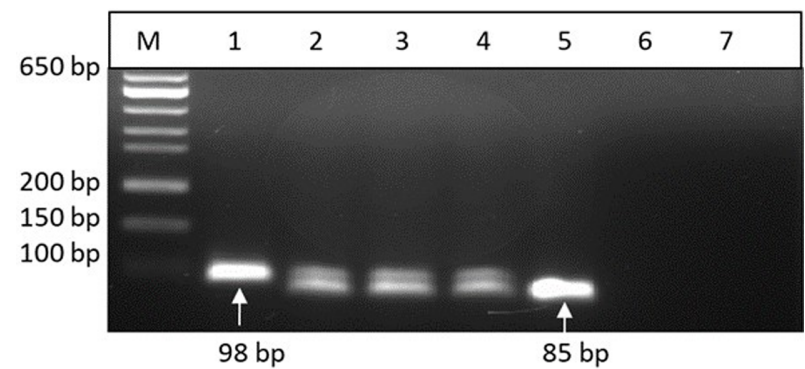

Fig. 4. Agarose gel electrophoresis of PCR product M: marker; 1: porcine positive template control, $98 \mathrm{bp} ; 2,3 \&$ 4: samples contains horse and porcine, $85 \& 98$ bp; 5 : horse positive template control, $85 \mathrm{bp} ; 6 \& 7$ : negative template control for horse and porcine, respectively.

respectively (Fig. 4).

\section{Specificity of EvaGreen based duplex real-time system}

Horse and porcine primers are specifically selected to detect horse and porcine tissue in meat mixtures. The assay utilizing the porcine and horse-specific primers was cross-tested on six meat species (chicken, donkey, turkey, cattle, chicken-meatball, and sausage mix) and six plant species (soybean, starch, corn, potato, wheat, and spice). It indicated that primers specific to the species of horse and porcine showed no cross-reaction with any of the non-target species until the $34^{\text {th }}$ cycle (reveals primer dimer or unspecific amplicon after $34^{\text {th }}$ cycle). This leads to the conclusion that the designed primers can only specifically amplify porcine and horse DNA and exclude the DNAs of other animal and plant species. Specificity of the duplex assay was established by performing melting curve analysis. EvaGreen based duplex real-time PCR assay was specific for each species investigated with slightly varying melting temperatures. In the present study, horse and porcine amplicons can easily be distinguished by Mps of horse $\left(82.5 \pm 0.2^{\circ} \mathrm{C}\right)$ and porcine $\left(78.0 \pm 0.3^{\circ} \mathrm{C}\right)$ due to the different lengths and GC composition of the two amplicons. Specificity of EvaGreen based duplex real-time system was confirmed by performing two independent experiments.

\section{The applicability and sensitivity of EvaGreen based} duplex real-time PCR assay

The analytical applicability and sensitivity of EvaGreen based simultaneous real-time PCR was determined by using DNAs obtained from a mixture of porcine and horse meats. A linear relationship between the input DNA and the $\mathrm{Cq}$ values was determined with a regression coeffici- 


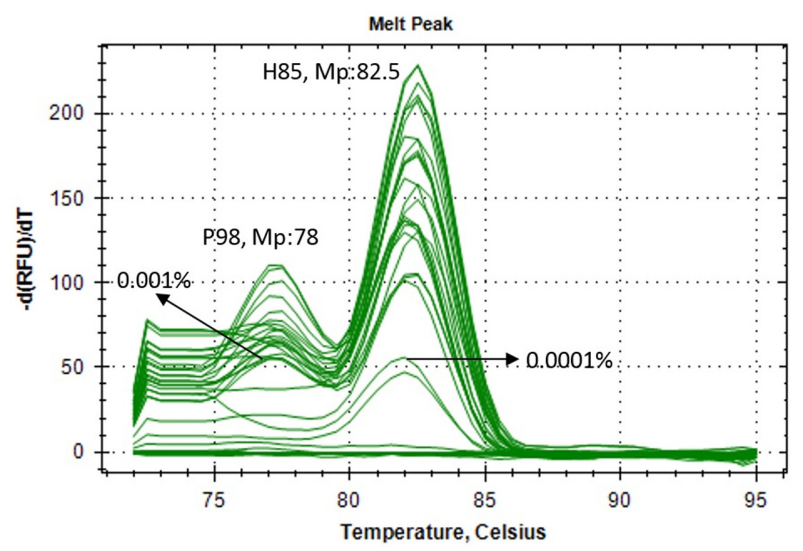

Fig. 5. The sensitivity of EvaGreen based duplex real-time PCR. H: horse; P: porcine; Mp: Melt peak.

ent $\left(\mathrm{R}^{2}\right)$ of 0.993 (Fig. 3). Simultaneous analytical assay sensitivity was $0.0001 \%$ and $0.001 \%$ for the specific duplex detection of horse and porcine in the reference sausage, respectively (Fig. 5). The analytical assay sensitivity was confirmed by performing two independent experiments. The absolute detection limit of the simultaneous real-time PCR was $0.00001 \mathrm{ng} / \mu \mathrm{L}$ for porcine and horse (Figure not shown).

\section{Quantification of unspecific and specific amplicon concentration}

For the detection of unspecific amplicons, primers of horse and porcine were used in simultaneous reaction without horse and porcine DNA template. Interestingly, horse primers yielded an unspecific amplicon which has Cq: 34.4 and $\mathrm{Mp}$ value $\left(81.7 \pm 0.3^{\circ} \mathrm{C}\right)$ similar to $\mathrm{Mp}$ of the positive control template $\left(82.5 \pm 0.2^{\circ} \mathrm{C}\right)$. Concentration of this unspecific amplicon was quantified by the standard curve constructed with the DNA obtained from serial dilution of an admixture containing horse and porcine meat (Table 1). All amplicons and primer dimers appearing after the 34th cycle were ignored due to the possibility of interference with specific amplicons and porcine crossreactivity of horse primers.

A non-specific signal cannot always be prevented, but its presence can be easily and reliably detected by performing melt and standard curve analysis of the PCR products. The $\mathrm{Cq}$ values from such assays should be scrutinized, and no meaningful quantification should be based on these data.

The temperature at which a DNA molecule melts depends on its length and sequence; therefore, if the PCR products consist of molecules of homogeneous length and sequence, a single thermal transition will be detected. On the other hand, the presence of more than one population of PCR products will be reflected as multiple thermal transitions in the fluorescence intensity. In this way, the fluorescence versus temperature is used to differentiate between specific and non-specific amplicons based on the Tm of the reaction end-products.

For decades, meat and meat products have become a trade object and possess high commercial value. Due to the increased international meat trade and high consumer demand, efforts to adulterate meat products have become widely prevalent (Hargin 1996; Siklenka 2004). We think that our research will provide a perfect support for the solution of these kinds of problems because it describes a simultaneous PCR assay for detection of horse and porcine materials in industrial meat products in a single reaction. The assay successfully developed is novel due to its ability to carry out amplification of two target genes (16S rRNA-tRNA and 12S RNA) simultaneously in a duplex format with EvaGreen based real-time PCR methods by using melting temperature discrimination (Fig. 2). As such, this unique property could be presented as a reference for the development of assays for detection and differentiation of other species, such as cattle, sheep, donkey, chicken, turkey etcetera.

EvaGreen assays are relatively easy to design and run and have better multiplexing capabilities than SYBR Green

Table 1. Results of melting and standard curve

\begin{tabular}{|c|c|c|c|c|}
\hline \multirow{2}{*}{$\begin{array}{c}\text { Mixture containing } \\
\text { porcine and horse }(\%)\end{array}$} & \multirow{2}{*}{$\begin{array}{c}\text { Cq values } \\
\text { means and SD }\end{array}$} & \multirow{2}{*}{$\begin{array}{l}\text { Detected levels } \\
(\sim \%)\end{array}$} & \multicolumn{2}{|c|}{ Mp values $\left(\mathrm{C}^{\circ}\right)$} \\
\hline & & & Porcine & Horse \\
\hline 10 & $16.22 \pm 02$ & 10 & $78 \pm 02$ & $82.5 \pm 03$ \\
\hline 1 & $19,92 \pm 02$ & 1.26 & $78 \pm 02$ & $82.5 \pm 03$ \\
\hline 0.1 & $23,37 \pm 01$ & 0.125 & $78 \pm 02$ & $82.5 \pm 03$ \\
\hline 0.01 & $25,87 \pm 00$ & 0.025 & $78 \pm 02$ & $82.5 \pm 03$ \\
\hline 0.001 & $29.15 \pm 03$ & 0.0031 & $78 \pm 02$ & $82.5 \pm 03$ \\
\hline 0.0001 & $30.09 \pm 02$ & 0.0016 & $78 \pm 02$ & $82.5 \pm 03$ \\
\hline Unknown amplicons & $34,34 \pm 01$ & 0.000309 & -- & $81.7 \pm 02$ \\
\hline
\end{tabular}

SD: Standard deviation. 
(Eischeid 2011; Fenicia et al., 2007; Frıcker et al., 2007; Mao et al., 2007; Yang et al., 2004). In our previous study, we achieved SYBR Green florescence based duplex real time PCR for identification of ruminant and poultry origins in foodstuff (Sakalar and Abasıyanık, 2012). In recent years, Pawar et al. (2014) reported a nucleic acid amplification assay based on SYBR Green I duplex realtime PCR to detect BoHV-1 in bovine semen. The assay included primers from BoHV-1 glycoprotein $\mathrm{C}(\mathrm{gC})$ and bovine growth hormone (bGH) genes for simultaneous detection of both the targets in a single tube. Mp analysis using EvaGreen, which we also used in this study, offers a sensitive, specific, rapid, and high-throughput method, fully integrated with multiplex real-time PCR, for the detection and differentiation of meat products.

In conclusion, we emphasize that EvaGreen based simultaneous real-time PCR is a powerful technology which is accurate, simple, economical and fast, with good sensitivity and specificity. This is achieved by maximizing amplification efficiency while ensuring specificity of the primers for each target. The potential of the described procedure to detect small amounts of porcine and horse DNA in industrial products may make it a useful tool for inspection programs to enforce labeling regulations on food products.

\section{References}

1. Asensio, L., González, I., García, T., and Martín, R. (2008) Determination of food authenticity by enzyme-linked immunosorbent assay (ELISA). Food Cont. 19, 1-8.

2. Cawthorn, D. M., Steinman, H. A., and Hoffman, L. C. (2013) A high incidence of species substitution and mislabelling detected in meat products sold in South Africa. Food Cont. 32, 440-449.

3. Commission Directive 2001/101/EC of 26 November 2001 amending Directive 2000/13/EC of the European Parliament and of the Council on the approximation of the laws of the Member States relating to the labelling, presentation and advertising of foodstuffs.

4. Eischeid, A. C. (2011) SYTO dyes and EvaGreen outperform SYBR Green in real-time PCR. BMC Res. Notes 4, 263.

5. Elızaquivel, P. and Aznar, R (2008) A multiplex RT-PCR reaction for simultaneous detection of Escherichia coli O157: H7, Salmonella spp. and Staphylococcus aureus on fresh, minimally processed vegetables. Food Microbiol. 25, 705-713.

6. EU/99/2013 (2013) Commission Recommendation EU/99/ 2013 of 19 February 2013 on a coordinated control plan with a view to establish the prevalence of fraudulent practices in the marketing of certain foods. Off. J. Eur. Commun. L 48, 28-32.

7. Fajardo, V., González, I., Martín, I., Rojas, M., Hernández, P.
E., García, T., and Martín, R (2008) Real-time PCR for detection and quantification of red deer (Cervus elaphus), fallow deer (Dama dama), and roe deer (Capreolus capreolus) in meat mixtures. Meat Sci. 79, 289-298.

8. Fenicia, L., Anniballi, F., De Medici, D., Delibato, E., and Aureli, P. (2007) SYBR green real-time PCR method to detect Clostridium botulinum type A. Appl. Environ. Microbiol. 73, 2891-2896.

9. Frıcker, M., Messelhausser, U., Busch, U., Scherer, S., and Ehlıng-Schulz, M. (2007) Diagnostic real-time PCR assays for the detection of emetic Bacillus cereus strains in foods and recent food-borne outbreaks. Appl. Environ. Microbiol. 73, $1892-1898$.

10. Fukushıma, H. and Tsunomor1, Y. (2005) Study of real-time PCR assays for rapid detection of food-borne pathogens. Kansenshogaku Zasshi 79, 644-655.

11. Hargin, K. D. (1996) Authenticity issues in meat and meat products. Meat Sci. 43, S227.

12. Köppel, R., Zimmerli, F., and Breitenmoser, A. (2009) Heptaplex real-time PCR for the identification and quantification of DNA from beef, pork, chicken, turkey, horse meat, sheep (mutton) and goat. Eur. Food Res. Technol. 230, 367-374.

13. López-Andreo, M., Garrido-Pertierra, A., and Puyet, A. (2006) Evaluation of post-polymerase chain reaction melting temperature analysis for meat species identification in mixed DNA samples. J. Agric. Food Chem. 54, 7973-7978.

14. Mao, F., Leung, W. Y., and Xin, X. (2007) Characterization of EvaGreen and the implication of its physicochemical properties for qPCR applications. BMC Biotechnol. 7, 76.

15. Martín, I., García, T., Fajardo, V., Rojas, M., Pegels, N., and Hernández, P. E. (2009) SYBR-Green real-time PCR approach for the detection and quantification of pig DNA in feedstuffs. Meat Sci. 82, 252-259.

16. Meyer, R., Hofelein, C., Luthy, J., and Candrian, U. (1995) Polymerase chain reaction restriction fragment length polymorphism analysis: A simple method for species identication in food. J. AOAC Int. 78, 1542-1551.

17. Natonek-Wisniewska, M., Slota, E., and Kalisz, B. (2009) Use of cytochrome B polymorphism for species identication of biological material derived from cattle, sheep, goats, roe deer and red deer. Folia Biol-Krakow. 58, 47-50.

18. Pafundo, S., Gullì, M., and Marmiroli, N. (2009) SYBR Green real-time PCR to detect almond in traces in processed food. Food Chem. 116, 811-815.

19. Pawar, S. S., Meshram, C. D., Singh, N. K., Saini, M., Mishra, B. P., and Gupta, P. K. (2014). Development of a SYBR Green I based duplex real-time PCR for detection of bovine herpesvirus-1 in semen. J. Virol. Methods 208, 6-10.

20. Pegels, N., García, T., Martín, R., and González, I. (2015) Market analysis of food and feed products for detection of horse DNA by a TaqMan real-time PCR. Food Anal. Methods 8, 489-498.

21. Rastogi, G., Dharne, M. S., Walujkar, S., Kumar, A., Patole, M. S., and Shouche, Y. S. (2007) Species identication and authentication of tissues of animal origin using mitochondrial and nuclear markers. Meat Sci. 76, 666-674. 
22. Şakalar, E. (2013) The practical analysis of food: The development of Sakalar quantication table of DNA (SQT-DNA). Food Chem. 141, 718-722.

23. Şakalar, E. and Abasıyanık, M. F. (2012) The development of duplex real-time PCR based on SYBR Green florescence for rapid identification of ruminant and poultry origins in foodstuff. Food Chem. 130, 1050-1054.

24. Siklenka, P., Fotta, M., Koréneková, B., Skalicka, M., Jacková, A., and Kottferová, J. (2004) Detection of specific bovine proteins in heat-processed meat product using rabbit antiserum. Bull. Vet. Inst. Pulawy 48, 277-281.

25. Stamoulis, P., Stamatis, C., Saradou, T., and Mamuris, Z. (2010) Development and application of molecular markers for poultry meat identication in food chain. Food Cont. 21, 1061-1065.

26. Walker, J. A., Hughes, D. A., Anders, B. A., Shewale, J., Sinha, S. K., and Batzer, M. A. (2004) Quantitative intra-short inter- spersed element PCR for species-specific DNA identification. Anal. Biochem. 316, 259-269.

27. Wang, W., Chen, K., and Xu, C. (2006) DNA quantification using EvaGreen and a real-time PCR instrument. Anal. Biochem. 356, 303-305.

28. Wissiack, R., de la Calle, B., Bordin, G., and Rodriguez, A. R. (2003) Screening test to detect meat adulteration through the determination of hemoglobin by cation exchange chromatography with diode array detection. Meat Sci. 64, 427-432.

29. Yaakob, B., Man, C., Mustafa, S., Mokhtar N. F. K., Nordin, R., and Sazili, A. Q. (2012) Porcine-specific polymerase chain reaction assay based on mitochondrial d-loop gene for identification of pork in raw meat. Int. J. Food Prop. 15, 134-144.

30. Yang, C., J1ang, Y., Huang, K., Zhu, C., Y1n, Y., Gong, J. H., and Yu, H. (2004). A real-time PCR assay for the detection and quantitation of Campylobacter jejuni using SYBR Green I and the LightCycler. Yale J. Biol. Med. 77, 125-132. 